\title{
Cryopreservation of primary human monocytes does not negatively affect their functionality or their ability to be labelled with radionuclides: basis for molecular imaging and cell therapy
}

Evangelia Pardali ${ }^{1}$, Timo Schmitz ${ }^{1}$, Andreas Borgscheiper ${ }^{1}$, Janette Iking $^{1}$, Lars Stegger ${ }^{2}$ and Johannes Waltenberger ${ }^{1,3^{*}}$

\begin{abstract}
Background: Circulating white blood cells crucially contribute to maintenance and repair of solid organs. Therefore, certain cell populations such as monocytes are attractive targets for use in molecular imaging and cell imaging, e.g. after labelling with radionuclides, as well as for cell therapies. However, the preparation of monocytes may require freezing and thawing to preserve cells for timely and standardised applications. Additional modifications of these cells such as radioisotope labelling are necessary prior to their application in vivo. We therefore tested the hypothesis whether cryopreservation of freshly isolated circulating human monocytes affects their functional phenotype or their suitability for radionuclide labelling.

Results: CD14+CD16- monocytes were isolated from human peripheral blood. They were either directly used for cellular assays and labelling or frozen down using cryoprotectants. In the latter case, cells were thawed prior to further use and analysed for survival, chemotactic responses to various growth factors and adhesion on endothelial cells. In addition, both fresh and cryopreserved monocytes were labelled with radiotracers followed by assessment of survival and chemotactic responses. In all functional assays performed, cryopreserved monocytes did not significantly differ from freshly isolated monocytes with regard to their functionality. Cryopreservation did not affect cell survival. There was no effect on the chemotactic response of monocytes towards different growth factors. Likewise, adhesion properties remained unchanged following cryopreservation. Moreover, the labelling efficiency was similar for freshly isolated and cryopreserved monocytes. Labelling did not negatively affect monocyte survival and function.

Conclusions: Our data indicate that cryopreservation of freshly isolated human primary monocytes is feasible and does not negatively affect their functionality when used for labelling and functional assessment.
\end{abstract}

Keywords: Monocytes, Cryopreservation, Migration, Adhesion, Radionuclide labelling

\footnotetext{
* Correspondence: Waltenberger@ukmuenster.de

'Department of Cardiovascular Medicine, University Hospital Münster,

Albert-Schweitzer-Campus 1, Building A1, 48149 Münster, Germany

${ }^{3}$ Cells-in-Motion Cluster of Excellence (EXC 1003 - CiM), University of

Münster, 48149 Münster, Germany

Full list of author information is available at the end of the article
} 


\section{Background}

Monocytes play an important role in inflammation and in host defence as they participate in both innate and adaptive immune responses. They are circulating mononuclear phagocyte-like cells which are derived from a common myeloid precursor in the bone marrow [1]. Although they do not proliferate outside the bone marrow, monocytes circulate for several days in the blood stream to peripheral tissues where they patrol blood vessels until they enter tissues and differentiate or until they die [2-4]. In addition, undifferentiated monocytes can reside in the subcapsular red pulp of the spleen in a much higher concentration than in the circulation [5]. Monocyte recruitment and infiltration into tissues are modulated by proinflammatory as well as metabolic stimuli. Upon tissue infiltration, monocytes can further differentiate irreversibly into tissue macrophages and/or dendritic cells following stimulation by different factors or induced by inflammation $[4,6]$.

Peripheral blood monocytes represent 5-10 \% of the human leukocytes in the peripheral blood. They show morphological heterogeneity and can be categorised in different subclasses depending on the expression of CD14, which is part of the lipopolysaccharide (LPS) receptor, and CD16, also known as the FcyRII receptor $[7,8]$. Human monocytes were classified into classical $\mathrm{CD} 14^{++} \mathrm{CD} 16^{-}$(85-90\% of monocytes) and nonclassical CD $14^{+} \mathrm{CD} 16^{++}$monocytes $(10-15 \%$ of the total monocytes). As a third subset, the intermediate $\mathrm{CD} 14^{+}$ ${ }^{+} \mathrm{CD} 16^{+}$monocytes was characterised [9]. Monocytes play crucial roles in the clearance of bacteria, viruses and toxic substances and in the eradication of apoptotic and necrotic cells. In addition, monocytes participate in the regulation of angiogenesis and arteriogenesis as well as tissue repair following injury [10].

However, increased accumulation of monocytes appears in inflammatory diseases such as rheumatoid arthritis, atherosclerosis, diabetes, hypertension, myocardial infarction and other cardiovascular diseases or cancer $[7,11,12]$. Thus, the ability of monocytes to mobilise and migrate to the sites of inflammation, angiogenesis/arteriogenesis and tissue repair is of great importance. Moreover, monocytes are the inflammatory cell type dominating the infarcted myocardium as they play an important role in heart repair as well [10, 13]. Moreover, monocytes may represent a therapeutic target after acute myocardial infarction since increased accumulation of monocytes lead to increased inflammation in the infarcted hearts $[10,13]$. So far, no data is available for human monocyte mobility and accumulation following myocardial infarction although different studies have focused on the characterisation of mouse monocyte mobility [13].
Chemotaxis, i.e. directed migration, is a crucial aspect of monocyte function. Several studies have shown that $\mathrm{CD} 14^{++} \mathrm{CD} 16^{-}$monocytes from patients with cardiovascular risk factors, such as diabetes mellitus, hypertension, smoking or hypercholesterolemia, show a chemotactic defect towards vascular endothelial growth factor-A (VEGF-A) and monocyte chemoattractant protein-1 (MCP-1) ligands [14-20]. However, it remains unknown how their chemotactic responses are affected in vivo and whether this has an effect on the development of cardiovascular diseases, arteriogenesis and cardiovascular healing.

Monocytes are attractive targets for use in molecular and cellular imaging as well as for cell therapy due to their important role in vascular repair and cardiovascular diseases. Cellular imaging of monocytes will allow their detection in the myocardium and their localization within the infarct zone, the border zone or the remote myocardium. In addition, cellular imaging would answer the question whether the phenotype of circulating monocytes in the blood stream correlates with the phenotype of monocytes in the atherosclerotic lesions or in the infarcted myocardium. Thus, techniques for tracking and localising human monocytes in vivo would be of major importance. Targeted imaging approaches require time-consuming modification of these cells prior to their application in vivo and imaging for a prolonged time (hours or more). The process of harvesting human cells from patients with acute myocardial infarction, analysis of cell function, radiolabelling of monocyte subfractions, administration of cells into mice and finally performing imaging with either planar and tomographic (single-photon emission computed tomography (SPECT)) scintigraphy or positron emission tomography (PET) is a long process. As a consequence, imaging must be performed outside office hours (i.e. in the late evening or during the night) under suboptimal working conditions (e.g. due to lack of imaging personnel). Therefore, intermediate freezing of the cells would be very beneficial for timely and standardised application. We therefore tested the hypothesis whether freezing and thawing, i.e. cryopreservation of circulating human monocytes affects the functional phenotype of these cells or their suitability for radioactive labelling.

\section{Methods}

\section{Monocyte isolation from peripheral human blood}

Monocytes were isolated from fresh human blood leukocyte reduction chamber of platelet apheresis sets enriched with white blood cells and platelets from healthy subjects recruited by the blood bank of the University Hospital Münster. The study was approved by the scientific and ethics committee of the University of Münster and conforms to the principles of the 
Declaration of Helsinki. Written informed consent was obtained from all subjects. Mononuclear cells (MNCs) were obtained from the blood by density centrifugation using Leucosep ${ }^{\odot}$ tubes $(50 \mathrm{ml}$, with filter, Greiner) and the density gradient media Histopaque $^{\ominus} 1077$ (Sigma) separation solution. "MACS Monocyte Isolation Kit II" (Miltenyi) was used for isolation of $\mathrm{CD} 14^{++} \mathrm{CD} 16^{-}$monocyte subpopulation. Following manufacturer's instructions, non-monocytes were magnetically labelled using a cocktail of biotinconjugated antibodies and anti-biotin MicroBeads. Depletion of these magnetically labelled cells was done through magnetic separation. Isolated monocytes were counted using CASY technology and washed once with serum-free RPMI-1640 medium before used for adhesion assay.

\section{Cryopreservation and subsequent thawing of human monocytes}

Monocytes were frozen for future use by suspending $10 \times 10^{6}$ cells $/ \mathrm{ml}$ in ice cold freezing medium $\mathrm{CTS}^{\circ}$ Synth-a-Freeze ${ }^{\bullet}$ Medium (Gibco). One-millilitre aliquots were dispensed to Biofreeze vials (Stratagene). The cells were transferred to a cryofreezing container (Mr. Frosty, Nalgene) and placed in a $-80{ }^{\circ} \mathrm{C}$ freezer. On the following day, the vials were transferred to liquid nitrogen and stored there for a duration of 2 days up to 4 weeks before use. The cells were thawed quickly in a $37{ }^{\circ} \mathrm{C}$ water bath and transferred into ten volumes of pre-warmed RPMI medium supplemented with $10 \%$ fetal bovine serum (FBS). Trypan blue exclusion indicated that the cells were $>95 \%$ viable just after thawing.

\section{Monocyte chemotaxis assays}

Chemotaxis was analysed as previously described [21]. Briefly, freshly isolated human monocytes or cryopreserved monocytes were resuspended in medium at a concentration of $0.5 \times 10^{6}$ cells $/ \mathrm{ml}$. Subsequently, monocytes were placed to the upper wells of a chemotactic chamber (Neuroprobe) and migrated towards chemotactic growth factors which were added to the lower wells of the chamber. Upper and lower wells were separated by a polycarbonate membrane (pore size $5 \mu \mathrm{m}$, Millipore). The cells were allowed to migrate for $90 \mathrm{~min}$ in a humidified incubator $\left(5 \% \mathrm{CO}_{2}\right)$ at $37{ }^{\circ} \mathrm{C}$. Adherent cells on polycarbonate membrane were fixed for $10 \mathrm{~min}$ using absolute ethanol and stained with Giemsa dye. The nonmigrated cells from the upper side of the membrane were scraped off gently with a cotton bud. Migrated cells were quantified by counting cells in five high-power fields (20× primary magnification) of four different wells per condition.

\section{Human umbilical vein endothelial cells}

Human umbilical vein endothelial cells (HUVECs) were isolated from anonymized donors according to the Declaration of Helsinki and approved by the ethics boards of the University of Münster (2009-537-f-S). HUVECs were cultivated as described before [22] on gelatin (1 \% in phosphate buffer saline (PBS)) coated T25 and T75 flasks in M199 (containing $20 \%$ FBS, $0.675 \%$ bovine pituitary extract (BPE), $0.125 \%$ heparin and $1.25 \%$ penicillin/streptomycin).

\section{Adhesion assays}

The ability of human monocytes to bind to HUVECs was measured using previously reported methods [23]. Endothelial cells cultured in 48-well dishes were either left unstimulated or stimulated for $4 \mathrm{~h}$ with $10 \mathrm{ng} / \mathrm{ml}$ human tumour necrosis factor $\alpha$ (hTNF $\alpha$ ) in M199 medium containing $1 \% \mathrm{FBS}$ at $37{ }^{\circ} \mathrm{C}$. Human primary monocytes were labelled with $4 \mathrm{pg} / \mathrm{ml}$ calcein (Invitrogen) at $37{ }^{\circ} \mathrm{C}$ for $15 \mathrm{~min}$. Cells were washed once to remove excess of calcein and resuspended in RPMI medium at a concentration of $2 \times 10^{5}$ cells $/ \mathrm{ml}$. Prior to the adhesion assay, HUVECs were rinsed three times, and $1 \times 10^{5}$ labelled monocytes per well were added. After $20 \mathrm{~min}$, unbound monocytes were removed and the cells were washed three times with $1 \times$ PBS to remove non-adherent monocytes. Pictures were taken in the middle of each well using a $5 \times$ objective, light at $490 \mathrm{~nm}$ with a Leica Microsystems DMI 3000B microscope, a shutter Leica Microsystems EL6000 and image software LAS V3.7. The number of cells was analysed by Image $1.45 \mathrm{~s}(\mathrm{NIH})$ with the particle analysis plug-in.

\section{Cell viability}

Cells were seeded in a 96-well plate at a density of 100,000 cells per well in RPMI medium. Cell density was determined every day using the CellTiter $96^{\circ}$ AQueous cell proliferation assay (MTS, Promega) according to the manufacturer's instructions. Briefly, $20 \mu \mathrm{l}$ of reagent was added to the test wells and incubated at $37^{\circ} \mathrm{C}$ for $1 \mathrm{~h}$ in $5 \%$ CO2. Optical density was measured at $490 \mathrm{~nm}$ by spectrophotometric analysis and viability was calculated as sample optical density divided by control optical density. As a negative control, $150 \mu \mathrm{l}$ of RPMI medium and $20 \mu \mathrm{l}$ MTS were used. In addition, the cells were stained with trypan blue and evaluated using light microscopy. The viability observed was always more than $80 \%$. All assays were performed in triplicates.

\section{Labelling of monocytes with ${ }^{99 \mathrm{~m}} \mathrm{Tc}-\mathrm{HMPAO}$ \\ ${ }^{99 m}$ Technetium-hexamethylpropyleneamineoxime $\left({ }^{99 \mathrm{~m}} \mathrm{Tc}-\mathrm{HMPAO}\right)$ was prepared using the stabilised Ceretec cobalt labelling kit (GE Healthcare, Buchler $\mathrm{GmbH} \&$ Co. KG, Braunschweig, Germany) according to}


the manufacturer's instructions. Fresh and cryopreserved monocytes $\left(7 \times 10^{6} /\right.$ sample) were resuspended in $100 \mu \mathrm{l}$ of $0.9 \% \mathrm{NaCl}$. Per sample, $150 \mathrm{MBq}$ of ${ }^{99 \mathrm{~m}} \mathrm{Tc}-\mathrm{HMPAO}$ was added and cells were incubated at room temperature for $20 \mathrm{~min}$. Cells were spun down at $1100 \mathrm{rpm}$ for $10 \mathrm{~min}$ and subsequently washed once with $1 \times$ PBS. Radioactivity was measured using an ISOMED dose calibrator (MED Nuklearmedizin-Technik Dresden GmbH, Dresden, Germany). Labelling efficiency (LE) was estimated using the following formula: LE $=[C /(C+W)] \times 100$, where $C$ is activity associated with the cells and $\mathrm{W}$ is activity associated with the wash.

\section{Reagents}

Recombinant human vascular endothelial growth factorA (VEGF-A) and placenta growth factor-1 (PlGF-1) were obtained from RELIATech $\mathrm{GmbH}$ (Braunschweig, Germany). Recombinant human transforming growth factor $\beta 1$ (TGF $\beta 1)$ and monocyte chemotactic protein-1 (MCP-1) were obtained from Peprotech GmBH (Hamburg, Germany). RPMI 1640 medium was purchased from Invitrogen (Karlsruhe; Germany) and fetal calf serum (FCS) from Biochrom AG (Berlin, Germany). Cell Titer $96^{\circ}$ non-radioactive cell proliferation assay was purchased from Promega (Madison, WI, USA). Histopaque separation solution was obtained from SigmaAldrich (Saint Louis, MO, USA).

\section{Statistical analysis}

Results are expressed as mean \pm SEM using GraphPad Prism (Version 5). To estimate the level of significance, a one-way ANOVA non-parametric Kruskal-Wallis test for unpaired samples with Dunn's post test or the Mann-Whitney test were used. A probability $(p)$ value of $<0.05$ was considered statistically significant. All calculations were performed using SPSS version $22\left(^{*} p<0.05\right.$, "** $\left.p<0.01,{ }^{* * * * *} p<0.001\right)$.

\section{Results}

Effects of cryopreservation on mononuclear cell viability

First, we characterised the effects of cryopreservation on the recovery of cryopreserved $\mathrm{CD} 14^{++} \mathrm{CD} 16^{-}$monocytes. As shown in Fig. 1a, cryopreservation resulted in $27.8 \pm$ $12 \%$ loss of monocytes after thawing. The viability of both fresh and cryopreserved cells was tested using a trypan blue exclusion assay. As shown in Fig. 1b, cell cryopreservation had no statistically significant effect on the ratio between alive and dead cells at $24 \mathrm{~h}$; however, the difference reaches statistical significance after $48 \mathrm{~h}$ both for freshly isolated and cryopreserved cells. Nevertheless, considering that the cryopreserved cells will be labelled and administrated immediately after thawing for live cell imaging shortly after injection into the recipient, the small reduction in number of living cells at $48 \mathrm{~h}$ post thawing may not affect the imaging results.

We further analysed the effects of cryopreservation on survival of human monocytes using the MTS CellTiter 96 AQueous One Solution cell proliferation assay. The data suggest that cryopreservation for short (2-4 days) or longer periods of time (4-5 weeks) did not affect survival of $\mathrm{CD} 14^{++} \mathrm{CD} 16^{-}$monocytes (Fig. 1c-e). Nevertheless, there is a slight increase in proliferation/survival of monocytes at $24 \mathrm{~h}$. The MTS compound is processed by cells into a coloured formazan product that is soluble in tissue culture medium. This conversion is presumably accomplished by NADPH or NADH produced by dehydrogenase enzymes in metabolically active cells. Thus, the small increase in the survival at $24 \mathrm{~h}$ may reflect increased metabolic activity of the cells at $24 \mathrm{~h}$ post isolation (freshly isolated monocytes) and $24 \mathrm{~h}$ after thawing (cryopreserved monocytes) and does not relate with monocyte proliferation.

\section{Chemotactic responses of fresh versus cryopreserved human monocytes}

One important aspect of monocyte function is chemotaxis, i.e. directed migration to sites of inflammation, neoangiogenesis or collateral growth, i.e. arteriogenesis. The effects of cryopreservation on mononuclear cell migration was analysed by comparing the migratory responses of freshly isolated and cryopreserved monocytes to various concentrations of the growth factors PlGF-1, VEGF-A, TGF $\beta 1$ and MCP-1 (Fig. 2). The results $(n=$ 20) demonstrate that both fresh and cryopreserved monocytes show significant migratory responses towards the different chemoattractants (Fig. 2a-d). Although there is a small reduction (5-15\%) of the chemotactic responses in cryopreserved monocytes, there is no significant difference $(p>0.05)$ when compared to freshly isolated monocytes (one-way ANOVA Kruskal-Wallis test with Dunn's post test).

\section{Cryopreservation does not affect monocyte adherence to endothelial cells}

An important aspect of monocyte function is their adherence to the endothelium, which in turn is the initial step of monocyte recruitment to inflammatory sites, followed by transmigration through the endothelium. Therefore, we analysed the effect of cryopreservation on monocyte adhesion to HUVECs. Adhesion of cells on unstimulated endothelial cells was set as $100 \%$. Our results $(n=6)$ suggest that both freshly isolated (100 and $202 \%)$ as well as cryopreserved monocytes (100 and $232.2 \%)$ adhere to both non-activated and TNF $\alpha$ activated HUVECs in a similar fashion (Fig. 3) and that there are no significant differences $(p>0.05)$ in their adhesion. 
a

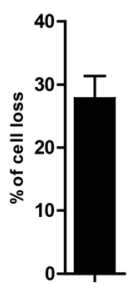

C 2-4 days
cryopreservation

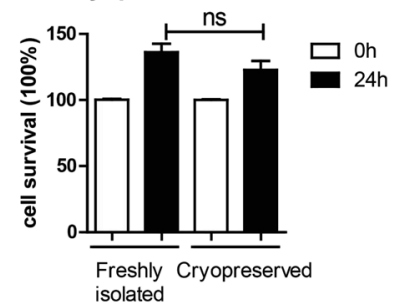

b

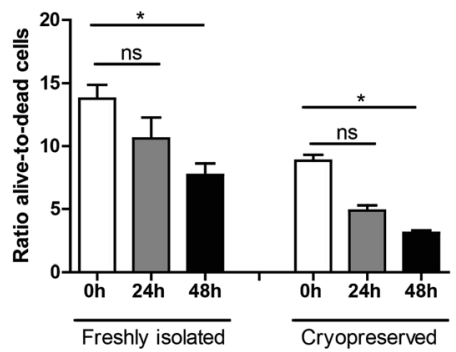

d 4-5 weeks
cryopreservation

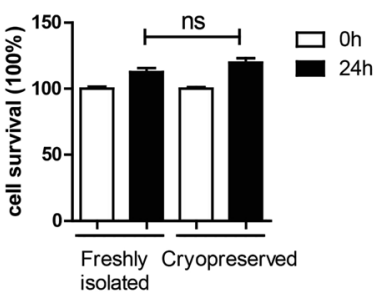

e 2 days -5 weeks cryopreservation

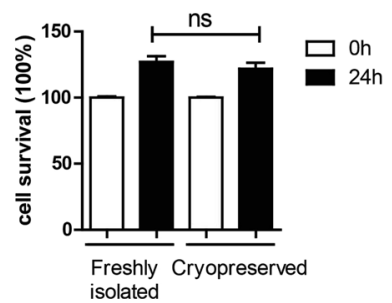

Fig. 1 Effects of cryopreservation on viability of $C D 14^{++} \mathrm{CD} 16^{-}$monocytes. a Recovery of cryopreserved human monocytes after thawing. b Freshly isolated and cryopreserved cells were analysed for their survival using a trypan blue exclusion method. Relative ratios of the alive-to-dead freshly isolated and cryopreserved monocytes were calculated. c-e Freshly isolated and cryopreserved cells were analysed with the MTS viability assay at $0 \mathrm{~h}, 24 \mathrm{~h}$ after isolation or thawing, $2-4$ weeks $(n=7)$ or $4-5$ weeks $(n=10)$ after cryopreservation. Statistics: Kruskal-Wallis test with Dunn's post test, $p$ value: ${ }^{*} p<0.05$

\section{Cryopreservation of human monocytes does not affect} their labelling with the radiopharmaceutical ${ }^{99 \mathrm{~m}} \mathrm{Tc}$-HMPAO or their cellular function

Since monocytes are putative targets for use in molecular and cellular imaging, there is an urgent need for the development of novel approaches (e.g. the establishment of specific protocols) to study mononuclear cell trafficking in vivo.
We sought to study whether labelling of human monocytes with radiopharmaceuticals for cell tracking in vivo is efficient and whether labelling does affect their function. Experiments were performed both for fresh unfrozen cells and for cryopreserved cells. We have chosen the radiopharmaceutical ${ }^{99 \mathrm{~m}} \mathrm{Tc}-\mathrm{HMPAO}$ which is established for cell labelling and suitable for planar and tomographic scintigraphy.
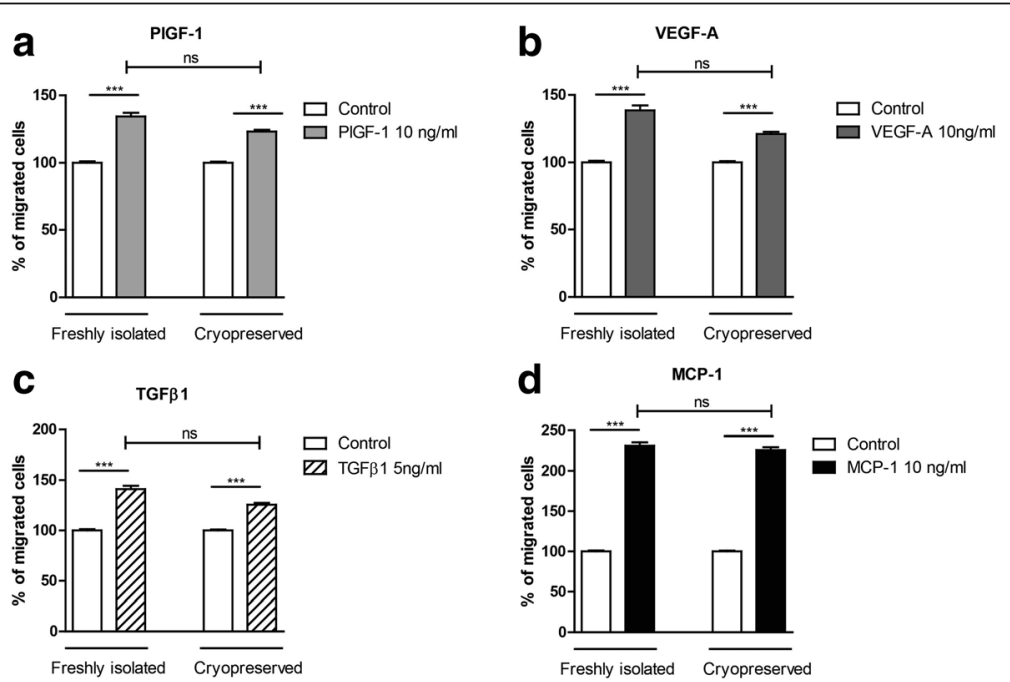

Fig. 2 Effects of cryopreservation on chemotaxis of $\mathrm{CD} 14^{++} \mathrm{CD} 16^{-}$monocyte. a-d Freshly isolated and cryopreserved monocytes were analysed for their chemotactic responses towards different concentrations of growth factors including PIGF1, VEGF-A, TGF $\beta$ and MCP-1 using a modified Boyden chamber chemotaxis assay $(n=20)$. Statistics: Kruskal-Wallis test with Dunn's post test, $p$ value: ${ }^{* *} p<0.001$ 

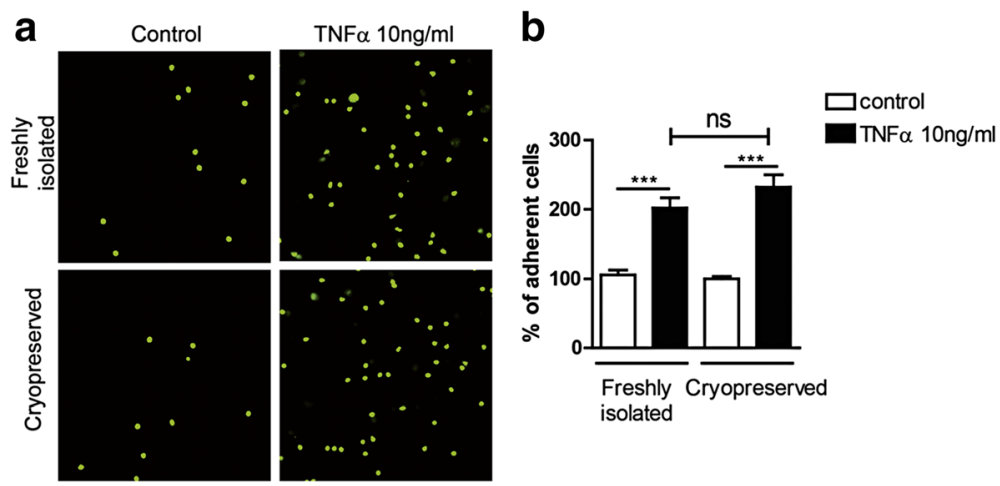

Fig. 3 Effect of cryopreservation of $\mathrm{CD} 14^{++} \mathrm{CD} 16^{-}$monocytes on adhesion to endothelial cells. a Freshly isolated and cryopreserved primary monocytes were allowed to adhere on TNFa stimulated or unstimulated HUVECs. $\mathbf{b}$ The number of adherent cells was quantified $(n=6)$. Statistics: Kruskal-Wallis test with Dunn's post test, $p$ value: ${ }^{* * *} p<0.001$

Labelling of fresh $\mathrm{CD} 14^{++} \mathrm{CD} 16^{-}$monocytes with ${ }^{99} \mathrm{~m}$ Tc-HMPAO resulted in labelling efficiency (LE) of $50.6 \%$ (Fig. 4a). Labelling did not affect cell survival of mononuclear cells as measured by the MTS cell survival assay $(n=12, p>0.05$; Fig. $4 \mathrm{~b})$. Moreover, we analysed the effects of ${ }^{99 \mathrm{~m}} \mathrm{Tc}-\mathrm{HMPAO}$ labelling on chemotactic responses. Basal migration of cells was set as $100 \%$. Migration towards VEGF-A and MCP-1 was consistent for both labelled (117.5 and 174.27 \%) and non-labelled monocytes (123.4 and $185.4 \%)$. No significant difference to unlabelled cells could be detected ( $n=12, p>0.05$; Fig. $4 \mathrm{~b})$.
These results suggest that ${ }^{99 \mathrm{~m}} \mathrm{Tc}-\mathrm{HMPAO}$ labelling of primary human monocytes does not strongly interfere with mononuclear cell viability and function.

Next, we studied the effects of cryopreservation on monocyte labelling. Cryopreserved human $\mathrm{CD} 14^{++} \mathrm{CD} 16$ - monocytes were labelled with ${ }^{99 \mathrm{~m}} \mathrm{Tc}-\mathrm{HMPAO}$. Labelling of cryopreserved monocytes with HMPAO resulted in a LE of 33.8 \% (Fig. 4a). The difference of LE of fresh and cryopreserved cells did not reach statistical significance $(n=12, p>0.05) .{ }^{99 \mathrm{~m}} \mathrm{Tc}-\mathrm{HMPAO}$ labelling did not affect viability of cryopreserved mononuclear cells as a

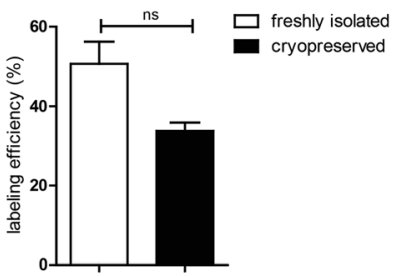

b

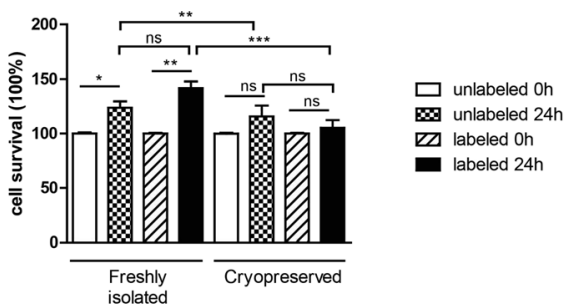

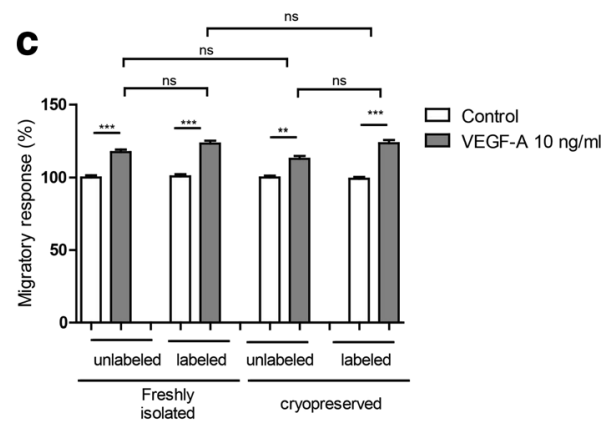

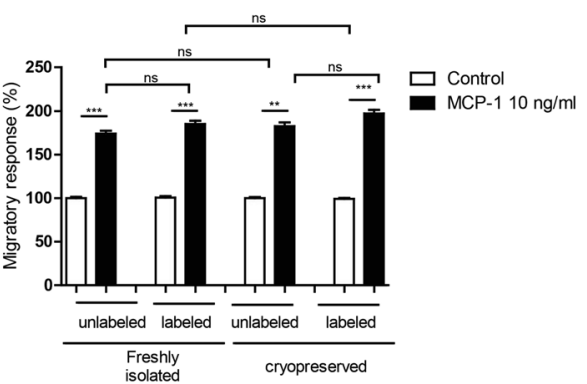

Fig. 4 Effects of cryopreservation on monocyte ${ }^{99 m} \mathrm{Tc}$-HMPAO labelling and functionality. Freshly isolated and cryopreserved monocytes were radiolabelled with $150 \mathrm{MBq}{ }^{99 \mathrm{~m}} \mathrm{Tc}-\mathrm{HMPAO}$ and analysed $\mathbf{a}$ for the efficiency of labelling, $\mathbf{b}$ for their survival using the MTS viability at 0 and $24 \mathrm{~h}$ after labelling and $\mathbf{c}$ for their migratory responses towards VEGF-A $(10 \mathrm{ng} / \mathrm{ml})$ and MCP-1 $(10 \mathrm{ng} / \mathrm{ml})$ in a modified Boyden chamber chemotaxis assay $(n=12)$. Statistics: Kruskal-Wallis test with Dunn's post test, or the Mann-Whitney test was performed, $p$ value: ${ }^{*} p<0.05 ;{ }^{* *} p<0.01 ;{ }^{* *} p<0.001$ 
measured by the MTS cell survival assay (Fig. 4b). Cryopreserved labelled monocytes migrated efficiently towards VEGF-A and MCP-1 and showed no significant differences to unlabelled cells (Fig. 4c). These results suggest that ${ }^{99 \mathrm{~m}} \mathrm{Tc}-\mathrm{HMPAO}$ labelling of cryopreserved monocytes is as efficient as using freshly isolated monocytes as labelling does not interfere with mononuclear cell viability and function.

\section{Discussion}

Monocytes are attractive targets for use in cellular imaging and for cell therapies as they play important roles in vascular repair and cardiovascular diseases. Both concepts require the ex vivo modification of cells prior to their application in vivo. An intermediate freezing step may be very beneficial to preserve cells for timely and standardised application in order to optimise imaging experiments, e.g. by avoiding imaging during off hours. For this, we sought to investigate whether freezing and thawing of circulating primary human monocytes affects the functional phenotype of these cells and their suitability for radioactive labelling.

Our results suggest that cryopreservation of primary human $\mathrm{CD} 14^{++} \mathrm{CD} 16^{-}$monocytes does not interfere with their survival as cryopreserved monocytes showed no deficits in viability compared to freshly isolated monocytes. In addition, our data show that the chemotactic responses of cryopreserved monocytes towards different concentrations of various growth factors are not negatively affected. Our results suggest that cryopreserved monocytes retain their ability to adhere to quiescent as well as activated endothelium to similar levels as freshly isolated monocytes do. Thus, primary monocytes can be isolated safely at any time point, cryopreserved and stored for later use. Moreover, cryopreserved monocytes can be used for functional testing such as endothelial adhesion assays and migration assays along with isolates from other types of patients and controls. Our results are in line with previous studies which demonstrated that cryopreservation of human monocytes does not affect viability, migration or differentiation of monocytes into macrophages and dendritic cells, IL6 secretion and cryopreserved monocyte could be used efficiently in the monocyte activation test (MAT) [24, 25].

Our study has shown that cryopreservation of human $\mathrm{CD} 14^{++} \mathrm{CD} 16^{-}$monocytes does not interfere with their suitability for radiolabelling with ${ }^{99 \mathrm{~m}} \mathrm{Tc}-\mathrm{HMPAO}$ for subsequent cell imaging. In fresh and cryopreserved monocytes, labelling with $150 \mathrm{MBq}{ }^{99 \mathrm{~m}} \mathrm{Tc}-\mathrm{HMPAO}$ does not affect mononuclear cell survival or their chemotactic responses The labelling efficiency was lower in our study for cryopreserved cells when compared to fresh cells, albeit not significantly. Cellular accumulation and retention of ${ }^{99 \mathrm{~m}} \mathrm{Tc}-\mathrm{HMPAO}$ relies on (1) the conversion of the lipophilic ${ }^{99 \mathrm{~m}} \mathrm{Tc}-\mathrm{HMPAO}$ complex into a hydrophilic complex. and 2) on the redox state of cells or the reaction of ${ }^{99 \mathrm{~m}} \mathrm{Tc}-\mathrm{HMPAO}$ with sulphydryl reagents like glutathione inside the cell [26-28]. It has been suggested that intracellular conversion of the hydrophobic TcHMPAO to a species which is incapable of rapid back diffusion involves interaction of ${ }^{99 \mathrm{~m}} \mathrm{Tc}-\mathrm{HMPAO}$ with glutathione. [29]. It was shown that cryopreservation of human and rat hepatocytes and human sperm results in reduced glutathione content and glutathioneconjugating capacity [30,31]. Based on these studies we could suggest that the slightly reduced labelling efficiency of cryopreserved human monocytes is due to reduced glutathione levels.

The establishment of a protocol to cryopreserve and revitalise primary human monocytes, which can be radiolabelled while retaining their viability and their functionality, represents a major advancement for both cellular imaging and cell therapy. This will allow the systematic usage of these cells as well as the comparison of cells from different patients. It has previously been shown that monocytes from either diabetes mellitus or hypercholesterolemic patients exhibit defective chemotactic responses to individual growth factors ex vivo including VEGF-A or MCP-1 [14-17, 20, 32]. It remains unclear whether reduced growth factor induced chemotactic responses are relevant for mononuclear cell function in vivo and to the development of atherosclerosis and/or to effective vascular healing in patients.

Based on the ability of monocytes and macrophages to phagocytose, several approaches have been developed for their targeted imaging in vivo. For example, different types of nanoparticles labelled with isotopes such as fluorine-18 [33] and copper-64 [34] or ultra-small superparamagnetic iron oxide (USPIO) nanoparticles were used to image monocytes/macrophages with positron emission tomography (PET) and magnetic resonance imaging (MRI), respectively [35]. In addition, the standard PET tracer 2-deoxy-2-[18F]fluoro-D-glucose ( $\left.\left[{ }^{18} \mathrm{~F}\right] \mathrm{FDG}\right)$, a glucose analogue, is taken up in vivo after intravenous injection by cells with a high metabolic rate such as mononuclear cells. It has been used for imaging inflammation of atherosclerotic plaques in coronary arteries [36-38]. Nevertheless, $\left[{ }^{18} \mathrm{~F}\right] \mathrm{FDG}$ is not specific for leukocytes in the atherosclerotic plaque. The same tracer could be used for in vitro labelling of inflammatory cells before injection for tracking mononuclear cells in vivo. However, $\left[{ }^{18} \mathrm{~F}\right] \mathrm{FDG}$ leakage out of these labelled cells would interfere with imaging specificity. It is thus of great importance to develop methods which will allow us to track and study primary human monocytes from different patients in vivo. The establishment of a method to cryopreserve and later efficiently label human monocytes ex vivo will allow us to study their localisation in vivo as well as their function and contribution to vascular healing in preclinical mouse models of 
angiogenesis and arteriogenesis. This way, we will gain more insights into the mononuclear cell dysfunction and how this translates into their role in vivo as well as their contribution to the development of vascular diseases.

Monocytes play an important role in myocardial infarction healing. However, they may have damaging effects on the myocardium in the early and late reperfusion period as well $[10,13,39]$. Therefore, imaging approaches to detect increased and sustained inflammation post MI will be of great importance for estimating the effect of monocytes on myocardial damage and repair. Moreover, ex vivo labelled monocytes can be used to localise them in vivo within the infarcted myocardium and the border zone. This may reveal hints to appreciate their potential contribution to post-infarct healing in preclinical mouse models as well as in consecutive clinical studies for in vivo trafficking of mononuclear cells in the human post-infarcted heart.

\section{Conclusions}

Taken together, our work demonstrates that freshly isolated and then cryopreserved monocytes, subsequently thawed and labelled with the radiotracer ${ }^{99 \mathrm{~m}} \mathrm{Tc}-\mathrm{HMPAO}$, retain all functional properties that have been tested so far. Therefore, monocyte cryopreservation as documented in our approach is feasible and will benefit studies on monocytes for cellular imaging and cell therapy.

\footnotetext{
Abbreviations

[ $\left.{ }^{18} \mathrm{~F}\right]$ FDG: 2-deoxy-2-[18F]fluoro-D-glucose; ${ }^{99 m}$ Tc-HMPAO: 99mTechnetiumhexamethylpropyleneamineoxime; hTNFa: Human tumour necrosis factor a; HUVECs: Human umbilical vein endothelial cells; LE: Labelling efficiency; MCP-1: Monocyte chemoattractant protein-1; MRI: Magnetic resonance imaging; PET: Positron emission tomography; PIGF-1: Placenta growth factor1; SPECT: Single-photon emission computed tomography; TGF $\beta 1$ : Transforming growth factor $\beta 1$; USPIO: Ultra-small superparamagnetic iron oxide; VEGF-A: Vascular endothelial growth factor-A

Funding

Our studies on the role of growth factor signalling in cardiovascular diseases are supported by the Deutsche Forschungsgemeinschaft (DFG), Collaborative Research Centre 656 Münster, project C12 and the Deutsche Stiftung für Herzforschung (DSHF), project F732/13.
}

\section{Authors' contributions}

EP was responsible for designing the experiments and analysis of the results and wrote the manuscript. TS and AB performed the experiments and analysed the results. Jl supported the migration experiments, proliferation studies and result analysis. EP, LS and JW were responsible for the design of the study and critically revised the manuscript. All authors read and approved the final manuscript.

\section{Competing interests}

The authors declare that they have no competing interests.

\section{Consent for publication}

Not applicable.

\section{Ethics approval and consent to participate}

The study was approved by the scientific and ethics committee of the University of Münster and conforms to the principles of the Declaration of Helsinki. Written informed consent was obtained from all subjects.

\section{Author details}

${ }^{1}$ Department of Cardiovascular Medicine, University Hospital Münster, Albert-Schweitzer-Campus 1, Building A1, 48149 Münster, Germany. ${ }^{2}$ Department of Nuclear Medicine, University Hospital Münster, 48149 Münster, Germany. ${ }^{3}$ Cells-in-Motion Cluster of Excellence (EXC 1003 - CiM), University of Münster, 48149 Münster, Germany.

Received: 16 September 2016 Accepted: 13 October 2016

Published online: 24 October 2016

\section{References}

1. Serbina NV, Pamer EG. Monocyte emigration from bone marrow during bacterial infection requires signals mediated by chemokine receptor CCR2. Nat Immunol. 2006;7:311-7. doi:10.1038/ni1309.

2. Auffray C, Fogg D, Garfa M, Elain G, Join-Lambert O, Kayal S, Sarnacki S, Cumano A, Lauvau G, Geissmann F. Monitoring of blood vessels and tissues by a population of monocytes with patrolling behavior. Science. 2007;317:666-70. doi:10.1126/science.1142883.

3. Auffray C, Fogg DK, Narni-Mancinelli E, Senechal B, Trouillet C, Saederup N, Leemput J, Bigot K, Campisi L, Abitbol M, et al. CX3CR1+ CD115+ CD135+ common macrophage/DC precursors and the role of CX3CR1 in their response to inflammation. J Exp Med. 2009;206:595-606. doi:10.1084/jem.20081385.

4. Auffray C, Sieweke MH, Geissmann F. Blood monocytes: development, heterogeneity, and relationship with dendritic cells. Annu Rev Immunol. 2009;27:669-92. doi:10.1146/annurev.immunol.021908.132557.

5. Swirski FK, Weissleder R, Pittet MJ. Heterogeneous in vivo behavior of monocyte subsets in atherosclerosis. Arterioscler Thromb Vasc Biol. 2009:29:1424-32. doi:10.1161/ATVBAHA.108.180521.

6. Liu K, Waskow C, Liu X, Yao K, Hoh J, Nussenzweig M. Origin of dendritic cells in peripheral lymphoid organs of mice. Nat Immunol. 2007;8:578-83. doi:10.1038/ni1462.

7. Heine GH, Ortiz A, Massy ZA, Lindholm B, Wiecek A, Martinez-Castelao A, Covic A, Goldsmith D, Suleymanlar G, London GM, et al. Monocyte subpopulations and cardiovascular risk in chronic kidney disease. Nat Rev Nephrol. 2012;8:362-9. doi:10.1038/nrneph.2012.41.

8. Ziegler-Heitbrock L. Monocyte subsets in man and other species. Cell Immunol. 2014;289:135-9. doi:10.1016/j.cellimm.2014.03.019.

9. Ancuta P, Liu KY, Misra V, Wacleche VS, Gosselin A, Zhou X, Gabuzda D. Transcriptional profiling reveals developmental relationship and distinct biological functions of CD16+ and CD16- monocyte subsets. BMC Genomics. 2009;10:403. doi:10.1186/1471-2164-10-403.

10. Pardali $\mathrm{E}$, Waltenberger J. Monocyte function and trafficking in cardiovascular disease. Thromb Haemost. 2012;108:804-11. doi:10.1160/TH12-04-0276.

11. Libby $P$, Nahrendorf M, Swirski FK. Monocyte heterogeneity in cardiovascular disease. Semin Immunopathol. 2013;35:553-62. doi:10.1007/s00281-013-0387-3.

12. Shi C, Pamer EG. Monocyte recruitment during infection and inflammation. Nat Rev Immunol. 2011;11:762-74. doi:10.1038/nri3070.

13. Dutta $P$, Nahrendorf M. Monocytes in myocardial infarction. Arterioscler Thromb Vasc Biol. 2015;35:1066-70. doi:10.1161/ATVBAHA.114.304652.

14. Czepluch FS, Bergler A, Waltenberger J. Hypercholesterolaemia impairs monocyte function in CAD patients. J Intern Med. 2007;261:201-4. doi:10.1111/j.1365-2796.2006.01753.x.

15. Dunaeva M, Voo S, van Oosterhoud C, Waltenberger J. Sonic hedgehog is a potent chemoattractant for human monocytes: diabetes mellitus inhibits Sonic hedgehog-induced monocyte chemotaxis. Basic Res Cardiol. 2010;105:61-71. doi:10.1007/s00395-009-0047-x.

16. Stadler N, Eggermann J, Voo S, Kranz A, Waltenberger J. Smokinginduced monocyte dysfunction is reversed by vitamin C supplementation in vivo. Arterioscler Thromb Vasc Biol. 2007;27:s120-126. doi:10.1161/01.ATV.0000250614.97896.4c.

17. Tchaikovski V, Olieslagers S, Bohmer FD, Waltenberger J. Diabetes mellitus activates signal transduction pathways resulting in vascular endothelial growth factor resistance of human monocytes. Circulation. 2009;120:150-9. doi:10.1161/CIRCULATIONAHA.108.817528.

18. Waltenberger J. Impaired collateral vessel development in diabetes: potential cellular mechanisms and therapeutic implications. Cardiovasc Res. 2001;49:554-60. 
19. Waltenberger J, Kranz A, Beyer M. Neovascularization in the human heart is associated with expression of VEGF-A and its receptors Flt-1 (VEGFR-1) and KDR (VEGFR-2). Results from cardiomyopexy in ischemic cardiomyopathy. Angiogenesis. 1999;3:345-51.

20. Waltenberger J, Lange J, Kranz A. Vascular endothelial growth factor-A-induced chemotaxis of monocytes is attenuated in patients with diabetes mellitus: a potential predictor for the individual capacity to develop collaterals. Circulation. 2000;102:185-90.

21. Olieslagers S, Pardali E, Tchaikovski V, ten Dijke P, Waltenberger J. TGF-beta1/ALK5-induced monocyte migration involves PI3K and p38 pathways and is not negatively affected by diabetes mellitus. Cardiovasc Res. 2011;91:510-8. doi:10.1093/cvr/cvr100.

22. Liu Z, Kobayashi K, van Dinther M, van Heiningen SH, Valdimarsdottir G, van Laar T, Scharpfenecker M, Lowik CW, Goumans MJ, Ten Dijke P, Pardali E. VEGF and inhibitors of TGFbeta type-I receptor kinase synergistically promote blood-vessel formation by inducing alpha5-integrin expression. J Cell Sci. 2009;122:3294-302. doi:10.1242/jcs.048942.

23. Hsu WY, Chao YW, Tsai YL, Lien CC, Chang CF, Deng MC, Ho LT, Kwok CF, Juan CC. Resistin induces monocyte-endothelial cell adhesion by increasing ICAM-1 and VCAM-1 expression in endothelial cells via p38MAPKdependent pathway. J Cell Physiol. 2011;226:2181-8. doi:10.1002/jcp.22555.

24. Koryakina A, Frey E, Bruegger P. Cryopreservation of human monocytes for pharmacopeial monocyte activation test. J Immunol Methods. 2014;405:181-91. doi:10.1016/j.jim.2014.01.005

25. Seager Danciger J, Lutz M, Hama S, Cruz D, Castrillo A, Lazaro J, Phillips R, Premack B, Berliner J. Method for large scale isolation, culture and cryopreservation of human monocytes suitable for chemotaxis, cellular adhesion assays, macrophage and dendritic cell differentiation. J Immunol Methods. 2004;288:123-34. doi:10.1016/j.jim.2004.03.003.

26. Jacquier-Sarlin MR, Polla BS, Slosman DO. Oxido-reductive state: the major determinant for cellular retention of technetium-99m-HMPAO. J Nucl Med. 1996:37:1413-6.

27. Babich JW. Technetium-99m-HMPAO retention and the role of glutathione: the debate continues. J Nucl Med. 1991;32:1681-3.

28. de Vries EF, Roca M, Jamar F, Israel O, Signore A. Guidelines for the labelling of leucocytes with (99m)Tc-HMPAO. Inflammation/Infection Taskgroup of the European Association of Nuclear Medicine. Eur J Nucl Med Mol Imaging. 2010;37(4):842-8. doi:10.1007/s00259-010-1394-4.

29. Neirinckx RD, Harrison RC, Forster AM, Burke JF, Anderson AR, Lassen NA. A model for the in vivo behavior of Tc-99m d, I-HMPAO in man. J Nucl Med. 1987;28:559.

30. Stevenson DJ, Morgan C, McLellan LI, Helen Grant M. Reduced glutathione levels and expression of the enzymes of glutathione synthesis in cryopreserved hepatocyte monolayer cultures. Toxicol In Vitro. 2007;21(3):527-32. doi:10.1016/j.tiv.2006.11.005.

31. Gadea J, Molla M, Selles E, Marco MA, Garcia-Vazquez FA, Gardon JC. Reduced glutathione content in human sperm is decreased after cryopreservation: effect of the addition of reduced glutathione to the freezing and thawing extenders. Cryobiology. 2011;62(1):40-6. doi:10.1016/j.cryobiol.2010.12.001.

32. Tchaikovski V, Tchaikovski S, Olieslagers S, Waltenberger J. Monocyte dysfunction as a previously unrecognized pathophysiological mechanism in ApoE-/- mice contributing to impaired arteriogenesis. Int J Cardiol. 2015;190:214-6. doi:10.1016/j.jicard.2015.04.188.

33. Devaraj NK, Keliher EJ, Thurber GM, Nahrendorf M, Weissleder R. 18F labeled nanoparticles for in vivo PET-CT imaging. Bioconjug Chem. 2009;20:397-401. doi:10.1021/bc8004649.

34. Nahrendorf $M$, Zhang $H$, Hembrador S, Panizzi P, Sosnovik DE, Aikawa E, Libby P, Swirski FK, Weissleder R. Nanoparticle PET-CT imaging of macrophages in inflammatory atherosclerosis. Circulation. 2008;117:379-87. doi:10.1161/CIRCULATIONAHA.107.741181

35. Nahrendorf M, Sosnovik DE, Weissleder R. MR-optical imaging of cardiovascular molecular targets. Basic Res Cardiol. 2008;103:87-94. doi:10.1007/s00395-008-0707-2.

36. Rogers IS, Nasir K, Figueroa AL, Cury RC, Hoffmann U, Vermylen DA, Brady TJ, Tawakol A. Feasibility of FDG imaging of the coronary arteries: comparison between acute coronary syndrome and stable angina. JACC Cardiovasc Imaging. 2010;3:388-97. doi:10.1016/j.jcmg.2010.01.004.

37. Rudd JH, Narula J, Strauss HW, Virmani R, Machac J, Klimas M, Tahara N, Fuster $\mathrm{V}$, Warburton EA, Fayad ZA, et al. Imaging atherosclerotic plaque inflammation by fluorodeoxyglucose with positron emission tomography: ready for prime time? J Am Coll Cardiol. 2010;55:2527-35. doi:10.1016/j.jacc.2009.12.061.

38. Wykrzykowska J, Lehman S, Williams G, Parker JA, Palmer MR, Varkey S, Kolodny G, Laham R. Imaging of inflamed and vulnerable plaque in coronary arteries with 18F-FDG PET/CT in patients with suppression of myocardial uptake using a low-carbohydrate, high-fat preparation. J Nucl Med. 2009:50:563-8. doi:10.2967/jnumed.108.055616.

39. Sosnovik DE, Nahrendorf M, Weissleder R. Targeted imaging of myocardial damage. Nat Clin Pract Cardiovasc Med. 2008;5 Suppl 2:S63-70. doi:10.1038/ncpcardio1115.

\section{Submit your manuscript to a SpringerOpen ${ }^{\circ}$ journal and benefit from:}

- Convenient online submission

- Rigorous peer review

- Immediate publication on acceptance

- Open access: articles freely available online

- High visibility within the field

- Retaining the copyright to your article

Submit your next manuscript at springeropen.com 